\title{
Influences of wide-narrow seeding on soil properties and winter wheat yields under conservation tillage in North China Plain
}

\author{
Hongnan $\mathrm{Hu}^{1}$, Caiyun $\mathrm{Lu}^{1}$, Qingjie Wang ${ }^{1 *}$, Hongwen $\mathrm{Li}^{1}$, Jin $\mathrm{He}^{1}$, Dijuan $\mathrm{Xu}^{2}$, Xianliang Wang ${ }^{1}$ \\ (1. College of Engineering, China Agricultural University, Beijing 100083, China \\ 2. Beijing Vocational College of Agriculture, Beijing 102208, China)
}

\begin{abstract}
In order to promote the winter wheat yield and guarantee seeding quality in double-cropping system, no-tillage or reduced tillage planting modes with different row spacing have been implemented to result in different levels of yield. A three-year (2012-2015) field experiment was conducted on the experimental farm at Zhuozhou of Hebei Province in North China Plain to compare winter wheat yield from the two planting modes: wide-narrow row space planting mode (WN) and uniform row space planting mode (UR) Both planting modes were performed under reduced tillage conditions with straw mulching. The results showed that in North China Plain WN had positive impacts on crop yield, yield components, leaf area index (LAI) and intercepted photosynthetically active radiation (IPAR) index. Comparing with the UR, IPAR and LAI index for WN were enhanced by $4.8 \%$ and $5.2 \%$, respectively. The average yield for $\mathrm{WN}$ was $7.2 \%$, significantly greater than that of UR under the same quantity and density. In addition, for WN mode, machinery could pass through with less blocking under large amount of straw mulching, which largely improved tillage efficiency and potentially popularized the conservation tillage technology in North China plain. It is therefore recommended that wide-narrow row space planting mode (WN) combined with reduced tillage and straw mulching be more suitable for conservation tillage in double-cropping pattern areas in North China Plain.
\end{abstract}

Keywords: winter wheat yield, wide-narrow seeding, conservation tillage, row spacing, LAI, IPAR

DOI: $10.25165 /$ j.ijabe.20181104.3399

Citation: Hu H N, Lu C Y, Wang Q J, Li H W, He J, Xu D J, et al. Influences of wide-narrow seeding on soil properties and winter wheat yields under conservation tillage in North China Plain. Int J Agric \& Biol Eng, 2018; 11(4): 74-80.

\section{Introduction}

Long term traditional intensive agriculture has been demonstrated to reduce crop yields because of its resultant soil structure degradation and soil erosion. Additionally, the large amount of crop straw failed to be utilized appropriately, and a lot of air pollutants were generated from the outdoor straw burning ${ }^{[1,2]}$. Therefore, conservation tillage which could increase water use efficiency, reduce wind and water erosion and decrease soil loss ${ }^{[3-5]}$ was introduced. However, when it comes to the double-cropping pattern which has been adopted in China since $1980^{[6]}$, seeding quality could not be guaranteed. In this cropping pattern, maize is seeded in early June, and harvested in mid-September, while winter wheat is immediately seeded in early October and harvested in the following June. Before wheat seeding under conservation tillage conditions, a large amount of unrotten maize straw remains in the field as coverage, resulting in the frequent occurrence of blocking

Received date: $2017-10-29 \quad$ Accepted date: $2018-04-28$

Biographies: Hongnan $\mathrm{Hu}, \mathrm{PhD}$ candidate, research interests: conservation agriculture machinery, Email: hongnanhu@qq.com; Caiyun Lu, PhD, Associate Professor, research interests: precision agriculture technology and equipment, Email: lucaiyun@cau.edu.cn; Hongwen Li, PhD, Professor, research interests: conservation agriculture, agriculture machine and equipment engineering, Email: lhwen@cau.edu.cn; Jin He, PhD, Professor, research interests: conservation agriculture and farm machine, Email: hejin@cau.edu.cn; Dijuan Xu, Master, Lecturer, research interests: agriculture machinery equipment, Email: xudijuan1982@163.com; Xianliang Wang, PhD candidate, research interests: conservation agriculture machinery, Email: 13126728942@126.com.

*Corresponding author: Qingjie Wang, PhD, Professor, research interests: conservation tillage and equipment. Mailing address: College of Engineering, China Agricultural University, No.17, Qinghua East Road, Haidian District, Beijing 100083, China. Email: wangqingjie@cau.edu.cn. issues of local seeders ${ }^{[7]}$. Accordingly, the wide-narrow row spacing planting mode achieved by broadening the space between seeding device was proposed, for its potential for anti-blocking and increasing yield. Under this mode, only half numbers of former furrow openers are used to apply one row of fertilizer and seed two rows of wheat. In this way, planting density can be guaranteed while the wider distance between furrow openers enables the maize straw to flow through, which is able to solve the blocking issues and on the premise of guaranteed seeding quantity.

The relationship between row spacing and crop yield has been frequently studied. Most of them focused on changing planting density by using different row spacing, and a substantial potential for increasing yields was demonstrated. Many researchers reported a strong influence of row spacing and planting density on yield of crops such as maize ${ }^{[8,9]}$, canola ${ }^{[10]}$, soybean ${ }^{[11]}$, and tomato ${ }^{[12]}$ It has also been indicated that the canopy structure of the crops, photosynthetic capacity, leaf area index (LAI), biomass could be improved by adjusting row spacing and planting density, and as a consequence the crop yield could be affected. As for wheat, William et al. ${ }^{[7]}$ found that winter wheat row spacing can be widened to at least $50 \mathrm{~cm}$ to facilitate conservation-tillage farming with equal grain and straw production when compared to narrower row spacing. Hussain et al. ${ }^{[13]}$ recommended that a row spacing of $20 \mathrm{~cm}$ could improve the wheat performance under drought stress in early growth season of wheat. Overall, the difference of a good agronomic option of winter wheat row spacing was mainly influenced by irrigation, tillage method, crop rotation scheme and so on.

In order to suit the condition of China, a planting mode of wide-narrow row based on domestic crop planting requirements was put forward. Under the wide-narrow row planting mode studied in this paper, row spacing was changed without any changes in whole planting density, in other words, in this planting 
mode a certain row was close to one of its adjacent rows while far away from the other, hence a constant planting density could be insured. Seeders that appropriate for this planting mode as well as conservation tillage conditions were designed years ago and have been widely applied in the North China Plain. The relationship between row spacing and yield was concerned in existing literatures. It is indicated that when the seeding quantity is guaranteed, the application of wide-narrow row spacing planting mode can increase ventilation and photosynthesis, while prevent disease and lodging, and finally increase production by more than $4 \%{ }^{[14]}$. Some researchers ${ }^{[15-17]}$ also suggested that wide-narrow row planting mode without changing planting density could enhance soil nutrition and moisture, reduce soil bulk density and improve LAI and radiation use efficiency (RUE), which all contribute to better growth and higher yield.

Although there were plenty of researches on wide-narrow row planting mode in China, most of them focused on maize and soybean, seldom research explored the potential impacts of wide-narrow row space planting on winter wheat yields, in addition, most of them did not take into account the influence of tillage practices such as no and seldom tillage. Therefore this study was conducted to aimed at evaluate the effect of winter wheat row spacing on yield under no or reduced tillage. The objectives of this study were to compare the changes of soil properties and crop yields of winter wheat under wide-narrow row spacing planting mode, and the uniform row spacing planting modes under no or reduced tillage double-cropping areas in the North China Plain.

\section{Materials and methods}

\subsection{Site and climate description}

The field experiment was conducted from October 2012 to June 2014 at the experimental farm of China Agricultural

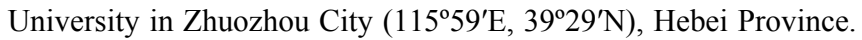
Zhuozhou has a semi-humid continental monsoon climate. The precipitation and temperature were monitored throughout the experiment by a solar-powered automatic weather monitoring station located at the experiment plots. The weather station is consisted of a main sensor and three assistant sensors, data are recorded automatically by data loggers. The meteorological conditions in Zhuozhou were illustrated in Figure 1. The temperature decreased from seeding season of winter wheat in October, then became warmer after January; and the maximum and minimum mean annual temperature during three cropping seasons from October to next April was $15^{\circ} \mathrm{C}$ and $-4.125^{\circ} \mathrm{C}$, respectively. The mean annual precipitation was $549.12 \mathrm{~mm}$, while the greatest monthly rainfall during the growth period of winter wheat was $24.5 \mathrm{~mm}$, which occurred in October.

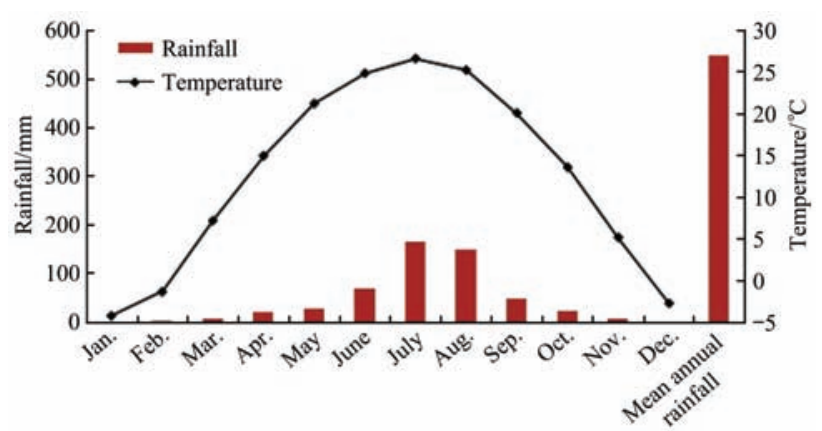

Figure 1 Mean annual rainfall (4 years) and distribution of mean monthly rainfall and temperature at Zhuozhou during the experimental years from 2011 to 2014
The soil texture in experimental plots is defined as silt loam according to the USDA soil taxonomy ${ }^{[18]}$, with the $\mathrm{pH}$ of 7.68 . Soil bulk density of the experimental site was predetermined from undisturbed soil samples, and the average soil bulk density was $1.20 \mathrm{~g} / \mathrm{m}^{3}$ at $0-10 \mathrm{~cm}$ soil depth, $1.28 \mathrm{~g} / \mathrm{m}^{3}$ at $10-20 \mathrm{~cm}$ soil depth, and $1.35 \mathrm{~g} / \mathrm{m}^{3}$ at $20-30 \mathrm{~cm}$ soil depth. Double cropping of winter wheat and summer maize is the dominant cropping system in this region, while conservation tillage had been practiced in this farm for 7 years.

\subsection{Experimental design}

The two factors experiments were carried out in a randomized complete block design, with three replications. Experimental blocks were divided according to the quantity of maize straw to guarantee similar experiment condition. Each plot was $45 \mathrm{~m}$ wide and $180 \mathrm{~m}$ long and the average amount of maize straw covered on plots was at least $2.87 \mathrm{~kg} / \mathrm{m}^{2}$. The experiment included two modes (treatments) (Figure 2), uniform row space planting mode (UR) and wide-narrow row space planting mode (WN), both modes were arranged after maize harvesting with the same straw mulching condition. In specific to the seeding operation, rotary strip tillage was installed in both UR and WN to increase the passing ability and rotary strip tillage depth was approximately $8-10 \mathrm{~cm}$.

In order to fulfill the different row spacing seeding treatments, UR arranged one row of fertilizer with one row of wheat seeder behind one furrow opener (Figure 2c), while WN was designed to have one row of fertilizer and two rows of wheat seeders on both sides of one fertilizer opener (Figure 2). That means, one unit of seeding device can place two rows of seeds and one row of fertilizer during one round of operation at $\mathrm{WN}$, so that the numbers of seeding devices and furrow openers in WN (Figure 2b) was half of the UR. For the WN, the space between two rows of wheat seed was " $10 \mathrm{~cm}+30 \mathrm{~cm}+10 \mathrm{~cm}+30 \mathrm{~cm}$ ", and the space between fertilizer openers was equal at $40 \mathrm{~cm}$ and the row space, while the distance between furrow openers of the UR were constant at $20 \mathrm{~cm}$ (Figure 2b). The depth difference between the fertilizer and seed was $5 \mathrm{~cm}$.

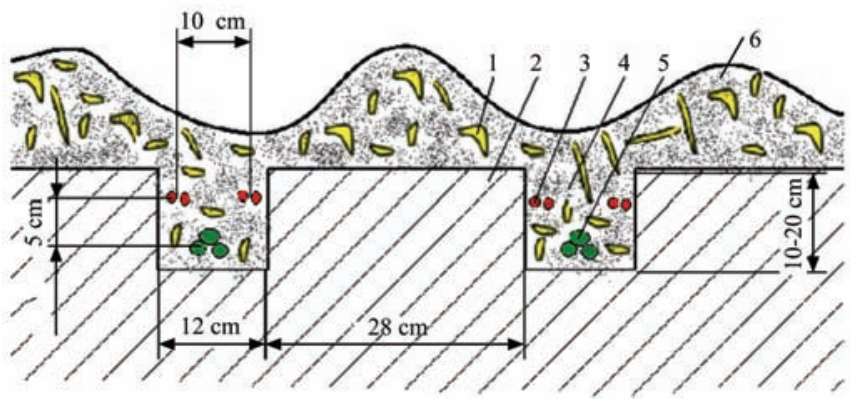

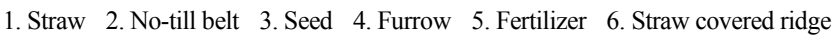
a. Section of the wide-narrow row space planting mode

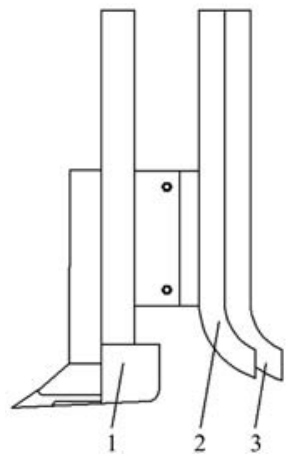

1. Fertilizer opener 2. Left seed tube 3. Right seed tube b. Seeding device for $\mathrm{WN}$ 


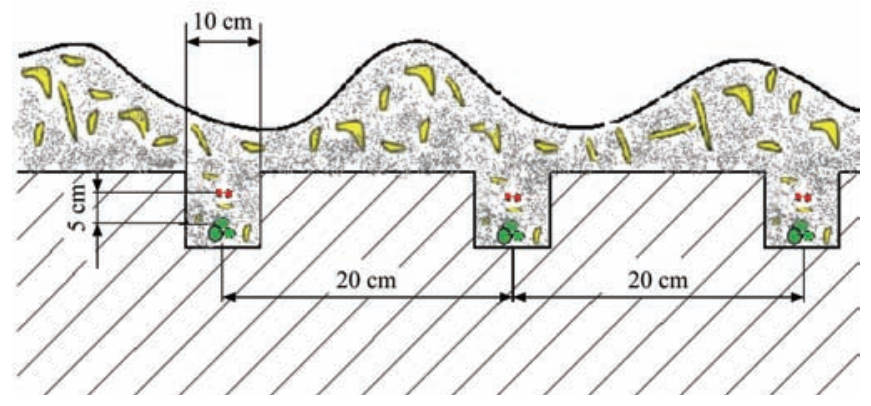

c. Section of the uniform row space planting mode

Figure 2 Fertilizer opener and two planting modes

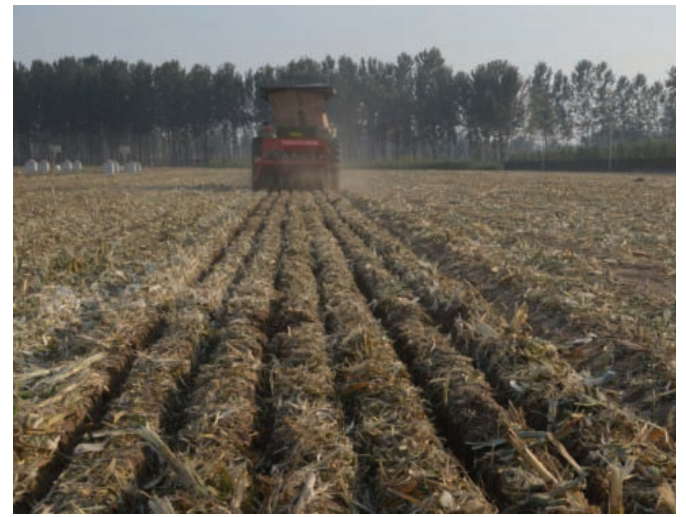

a. 2BMFS-6 no-till wheat seeder for UR

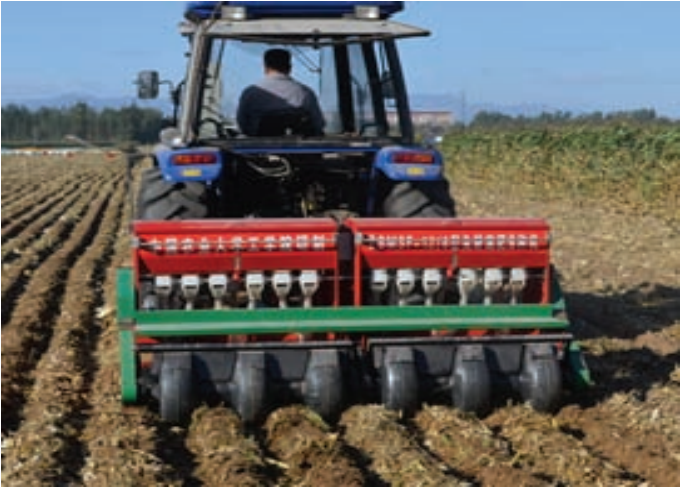

b. 2BMDS-12 no-till wheat seeder for WN

Figure 3 Operation treatments for UR and WN

Sub-soiling was finished before seeding every three years and all the previous maize straw was remained in the field. The treatments operation for UR and WN are presented in Figure 3. A 2BMFS-6 wheat seeder (Figure 3a) matched with a $37 \mathrm{~kW}$ Class tractor was used for seeding winter wheat under UR treatments in this study. The machine seeded 6 rows of winter wheat for the uniform row spacing $(20 \mathrm{~cm})$ with 6 units of seeding devices. The seeder cleans strips by residue chopping and rotary hoeing in front of knife type tine openers, so that a fluted roller type seed metering system can drop the seed for wheat after maize harvesting. The metal press wheels were used to place and to firm seeds and fertilizer at depth of $5 \mathrm{~cm}$ and $10 \mathrm{~cm}$, respectively. The 2BMDS-12 type wheat seeder (Figure 3b), also matched with a $37 \mathrm{~kW}$ Class tractor, was used for WN treatments. It had 6 units of seeding devices (Figure $2 \mathrm{~b}$ ) but could seed 12 rows of winter wheat for wide-narrow row spacing $(10 \mathrm{~cm}+30 \mathrm{~cm}+10 \mathrm{~cm}$ $+30 \mathrm{~cm})$. In order words, under $\mathrm{WN}$ treatment fewer furrow openers were used for same planting quantity, so that the straw covered situation were different between UR and WN. In UR, the straw distributed evenly on both no-till belts and seed belts while in $\mathrm{WN}$, straw were gathered on no-till belts.
Winter wheat (Ken wheat lu 9) was used in the test and irrigation was applied by spraying irrigation machine two times during growth season, the first time was in late November before it was going to freeze and the other time was in the next March just after the winter dormancy of winter wheat. The irrigation amount was recorded by a flow meter.

\subsection{Measured parameters}

Soil water storage: The soil volumetric moisture content (VMC) was detected in real time by Time Domain Reflectometry (TDR) soil moisture tester (Campbell Scientific, Inc. in Logan, UT USA). This instrument mainly consists of a solar panel, an accumulator, a mainframe, an extension and a probe sensor, which can record and wirelessly transmit the data automatically. The error of it was designed to be $\pm 2.5 \%$ in dry ground and $\pm 0.6 \%$ in saturated soil. VWC of seed belts was monitored through October to next June for three years at 0-5, 5-10, 10-20, 20-30, 30-40, 40-60, $60-80,80-100 \mathrm{~cm}$ soil depth. The values of monthly VMC are the average data automatically recorded by the tester. Soil water storage (WS) was then calculated by

$$
W S=V M C \times D
$$

where, $W S$ is soil water storage, \%; VMC is soil volumetric moisture content, $\%$; $D$ is soil depth, $\mathrm{mm}$.

Soil temperature: Soil temperature at $5 \mathrm{~cm}$ and $15 \mathrm{~cm}$ soil depth was measured by HOBO U30 data logger (Onset Computer Corporation, USA). It consisted of soil temperature sensors, a data collection device, a fixing device, a grounding device and a solar panel. The data collection device and grounding device were mounted on the fixing device. The temperature sensors were connected to the data collection device by network interface. The temperature reading was non-volatile memory and the data were transferred to a computer. Three HOBO U30 data loggers, each with four sensors at $5 \mathrm{~cm}$ and $15 \mathrm{~cm}$ respectively, were positioned randomly in each block. Soil temperature was measured every four hours (from 8:00 to 20:00) a day during the growth season of winter wheat from 5 th October to 8 th June in each of the three experimental years.

Photosynthesis and leaf area index (LAI): Leaf Area Index (LAI) is defined as the sum of the area of plant photosynthetic tissue per unit area on ground. LAI represents the ability of the crop to intercept solar radiation and was used for monitoring crop growth and estimating yields ${ }^{[19]}$. Photosynthetically Active Radiation (PAR) is the energy basis of plant growth, which means accumulated biomass of the plants has a close relation with PAR and LAI can be calculated by PAR ${ }^{[20-22]}$. We can calculate LAI by PAR according to Beer's Law:

$$
\mathrm{IPAR}=\mathrm{PAR}[1-\exp (-k \times L A I)]
$$

where, PAR is photosynthetically active radiation; IPAR is Intercepted photosynthetically active radiation; $k$ is extinction coefficient; and LAI is leaf area index.

SunScan Canopy Analysis System (SSCAS), made by Delta-T Devices Ltd in Cambridge UK, was used to evaluate Intercepted Photosynthetically Active Radiation (IPAR) and Leaf Area Index (LAI). SSCAS consists of Beam Fraction Sensor (BFS), 1 meter long SunScan probe and personal digital assistant (PDA). There are two sensors on BFS to measure PAR and transmitted photosynthetically active radiation (TPAR), respectively. And IPAR was then calculated as ${ }^{[21]}$ :

$$
\mathrm{IPAR}=\mathrm{PAR}-\mathrm{TPAR}
$$

Traditional method evaluating of LAI is measuring leaf area directly, which will destroy the plants and bring about irreversible loss. Using SSCAS can measure without blade damage and the 
measurements of observation object can be repeated ${ }^{[22]}$. BFS was settled above the top of plants to ensure all photosynthetic radiation can be caught, and SunScan probe stretched into the lowest leaves of wheat. Solar incident angle has great influence on the photosynthetic radiation, so that the time of measurement should be consistent and the diversity of solar incident angle should be minimal to make sure the error is accepted. Also, measurement should be arranged in sunny, gentle breeze days. During late March to late May, winter wheat goes through several stages tillering stage, elongation stage and blooming stage - and then goes ripe. Winter wheat LAI had been measured from late March to late May during the four years, because when the wheat getting ripe, leaves turning yellow and will also absorb solar radiation ${ }^{[21]}$ and the measurement was usually inaccurate. For tillering stage and elongation stage measurement, small plants and fewer canopies resulted in large error, so that three rows were chosen randomly and the data of each row was the average value of the data from three positions. Probe was placed at the middle of every two rows of winter wheat, the right side of one row of winter wheat and at the left side of another row of winter wheat. For elongation stage measurement, due to the winter wheat sealing ridge, eight rows were chosen randomly for each treatment, at this time the value was measured at the middle of every two rows and final results were the average value of the eight measurements. Also, the best measurement period of SSCAS is 9:00-11:00 a.m. and 13:0015:00 p.m.

Wheat yield and some yield components: Yield components, including the spike number, kernel number per spike and 1000-kernel weight, were also measured each year in mid-June. In specific, three $1 \mathrm{~m} \times 1 \mathrm{~m}$ winter wheat were collected by hand randomly at the center of each field plot and subjected to counting to assess the number of ears and grains per ear. The 1000-kernel weight (TKW) was calculated as the mean weight of three sets of 1000 grains per plot with an analytical balance accurate to $0.01 \mathrm{~g}$ (Mettler-ML104). The grain yield was determined when winter was at $13 \%$ moisture content.

\subsection{Statistical Analysis}

Mean values, standard deviations (SD) and standard errors (SE) of soil water content, soil temperature, IPAR, LAI and all the yield components were calculated. ANOVA was used to ascribe the effects of row spacing on the measured variables. When ANOVA indicated a significant F-value, multiple comparisons of annual mean values were performed by the least significant difference method (LSD). The SPSS analytical software package (2003) was used for all the statistical analysis.

\section{Results}

\subsection{Soil water storage}

Figure 4 shows the soil water storage following harvest from October 2012 to June 2015 for the two tillage modes in Zhuozhou. In the first two years, soil water storage was significantly different $(p<0.05)$ between two treatments from December to next June, but not significantly different from October to November. From December to February UR soil water storage was lower and then this tendency changed, soil water storage in UR was much higher than WN from March to June. In the last year, soil water storage was significantly different $(p<0.05)$ between two treatments from January to June, but not significantly different from October to December. The differences of soil water storage deviated widely among months, and the maximum difference was $59 \mathrm{~mm}$ (in March 2015), which accounted for almost $40 \%$ of entire soil water storage in year 2015 of the UR.
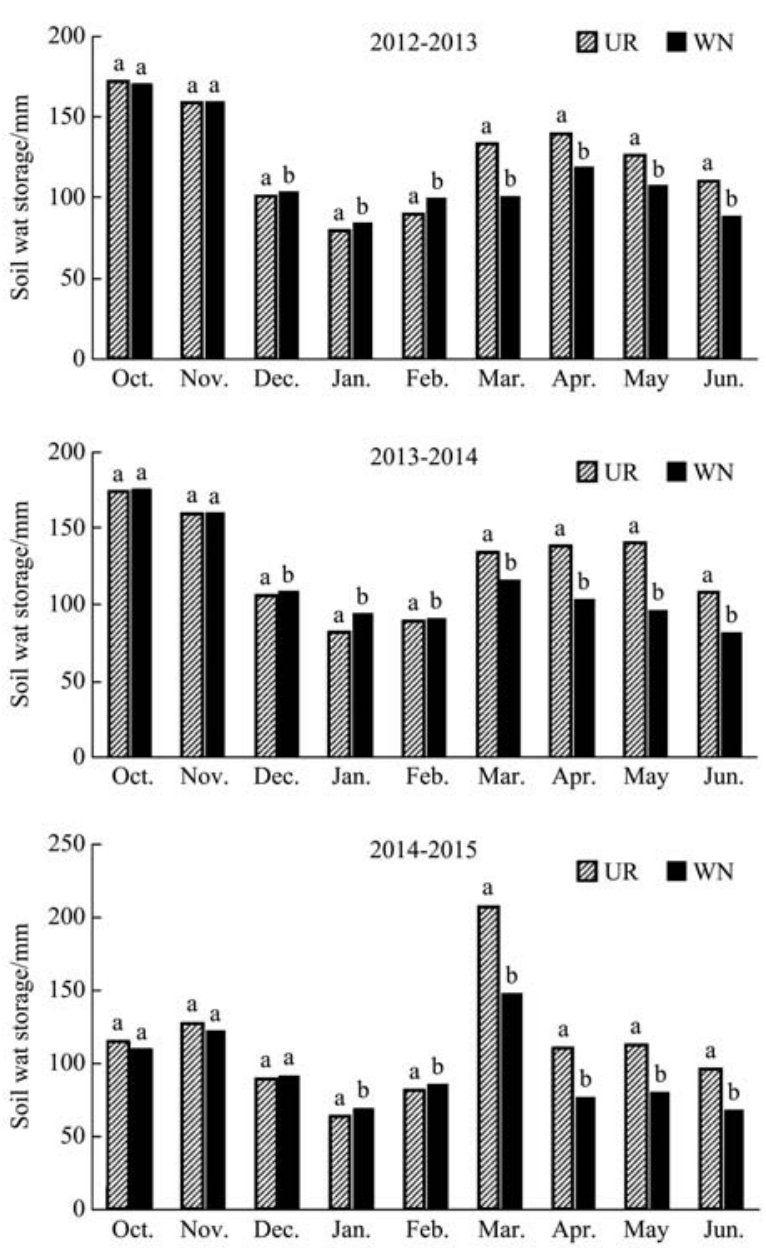

Figure 4 Mean monthly soil water storage at Zhuozhou during the experimental years. Precipitation of each year were different, so the soil water storage cannot be compared between different years. Values within a column in the same time followed by different letters are significantly different $(p<0.05)$

\subsection{Soil temperature}

Soil temperature at $5 \mathrm{~cm}$ and $15 \mathrm{~cm}$ soil depths from October to June each year for the WN and UR treatments is presented in Figure 5. In general, the soil temperature at both layers were well synchronized with the air temperature, and $\mathrm{WN}$ had greater soil temperature than the UR (Figure 5). The soil temperature differences were more pronounced in April and October, with the maximum difference of $2.375^{\circ} \mathrm{C}$ at $5 \mathrm{~cm}$ layer in October 2014 and $1.7^{\circ} \mathrm{C}$ at $15 \mathrm{~cm}$ layer in April 2013. In particular, the soil temperature of $\mathrm{WN}$ rose faster when approaching spring but dropped more slowly when approaching winter after October.

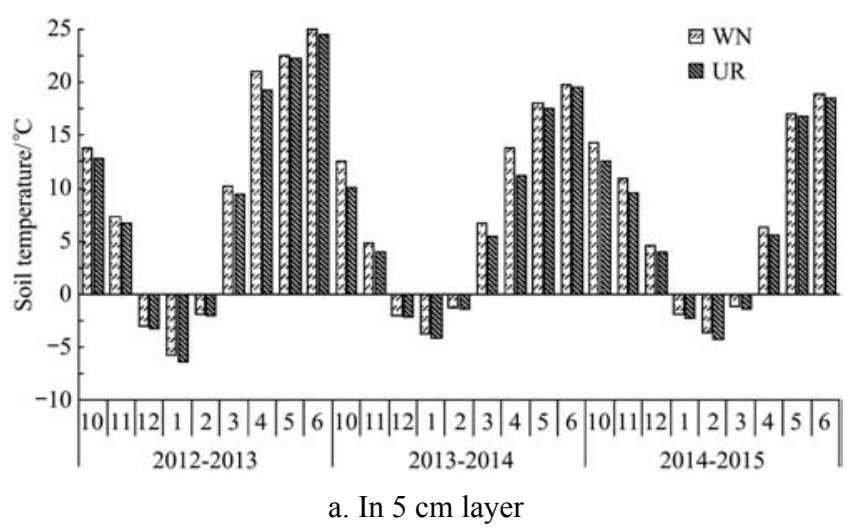




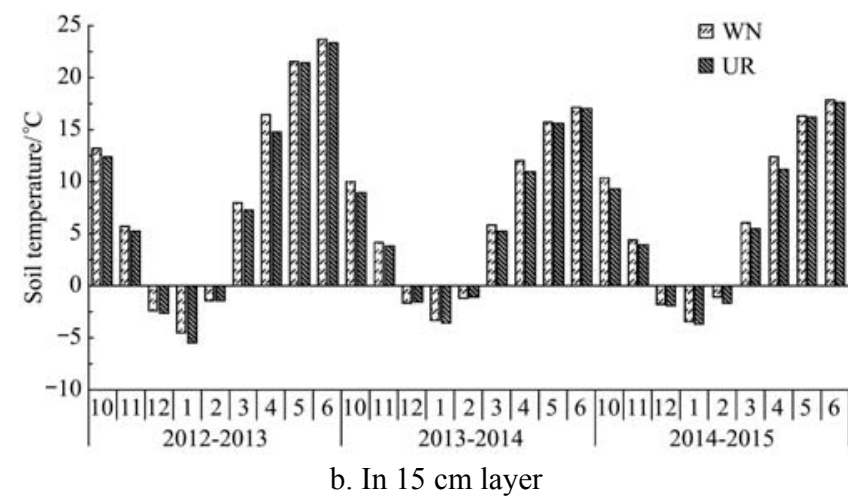

Figure 5 Mean monthly soil temperature (3 years) at Zhuozhou during the experimental years of 2012-2015

\subsection{Photosynthesis and LAI}

Table1 shows on the changes of intercepted photosynthetically active radiation (IPAR) between $\mathrm{WN}$ and UR. Throughout the growing season of winter wheat, the IPAR from both WN and UR consistently rose from late March to early May, peaked in early May, and then went down. In general, the IPAR of WN was significantly greater $(p<0.05)$ than that of the UR, except for early April of 2014, early May of 2013 and 2014, mid May of 2014 and late May in 2014 and 2015. In particular, the IPAR value of UR was even a little bit higher than WN in late May.

Treatment effects on Leaf Area Index (LAI) in our study are listed in Table 2. Similar to the IPAR, the LAI was significantly different $(p<0.05)$ between WN and UR, except for late March of 2015 and mid May of 2013 and 2015. The peak value of LAI was in late April, earlier than the IPAR which was in early May. In late April of 2015, IPAR value of WN was $4.8 \%$ higher than the UR treatment, LAI value of WN was $5.2 \%$ higher.

Table 1 IPAR at Zhuozhou

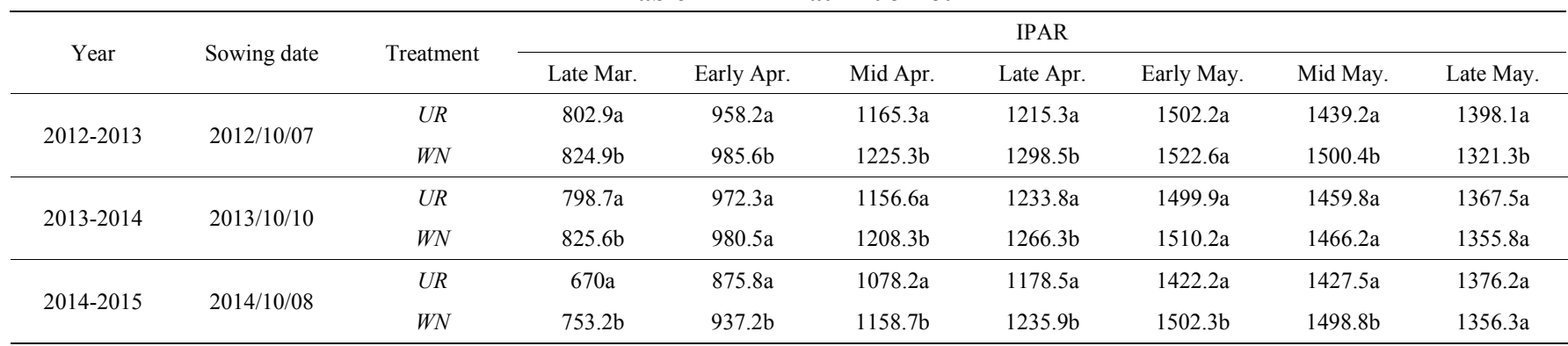

Note: Values within a column in the same time followed by different letters are significantly different $(p<0.05)$.

Table 2 LAI at Zhuozhou

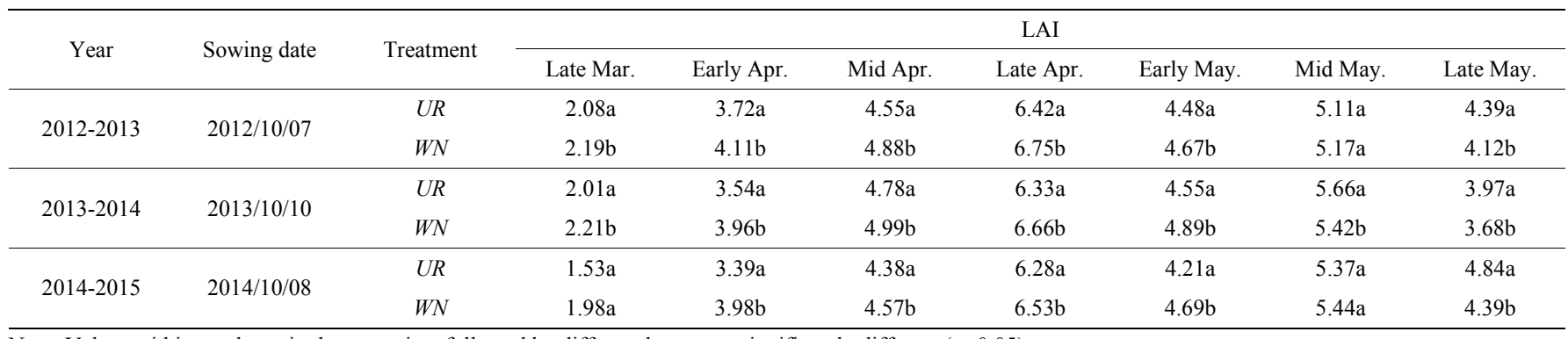

Note: Values within a column in the same time followed by different letters are significantly different $(p<0.05)$.

\subsection{Wheat yield and some yield components}

The highest total yield for winter wheat was WN (Table 3). In general, the crop yield of the two treatments for three years was significantly different $(p<0.05)$. The average yield of three years for UR and WN was $7160.3 \mathrm{~kg} / \mathrm{hm}^{2}$ and $7560 \mathrm{~kg} / \mathrm{hm}^{2}$, respectively. The yield difference was the highest in 2013 by $519 \mathrm{~kg} / \mathrm{hm}^{2}$ (WN > UR by $7.2 \%$ ), and the minimal difference was in 2015 by

\section{Table 3 Yield and yield components at Zhuozhou}

\begin{tabular}{cccccc}
\hline Year & Treatment & $\begin{array}{c}\text { Spike } \\
\text { number/m }\end{array}$ & $\begin{array}{c}\text { Kernel number } \\
\text { per spike }\end{array}$ & $\begin{array}{c}\text { 1000-kernel } \\
\text { weight/g }\end{array}$ & $\begin{array}{c}\text { Yield } \\
/ \mathrm{kg} \cdot \mathrm{hm}^{-2}\end{array}$ \\
\hline \multirow{2}{*}{$2012-2013$} & $U R$ & 625.8 & 29.5 & 33.2 & $7239 \mathrm{a}$ \\
& $W N$ & 675.3 & 30.8 & 34.1 & $7758 \mathrm{~b}$ \\
\hline \multirow{2}{*}{$2013-2014$} & $U R$ & 693.4 & 28.6 & 33.6 & $7255 \mathrm{a}$ \\
& $W N$ & 721.5 & 29.3 & 33.9 & $7688 \mathrm{~b}$ \\
\hline \multirow{2}{*}{$2014-2015$} & $U R$ & 655.3 & 29.1 & 33 & $6987 \mathrm{a}$ \\
& $W N$ & 695.5 & 29.4 & 33.5 & $7234 \mathrm{~b}$ \\
\hline \multirow{2}{*}{ Average } & $U R$ & 658.2 & 29.1 & 33.3 & 7160.3 \\
& $W N$ & 697.4 & 29.8 & 33.8 & 7560 \\
\hline
\end{tabular}

Note: Values within a column in the same time followed by different letters are significantly different $(p<0.05)$.
$247 \mathrm{~kg} / \mathrm{hm}^{2}$ (i.e., 3.5\%). The spike number, kernel number per spike and 1000-kernel weight were all greater under the WN than under the UR for all the four years in our study. The maximum differences in same year for the spike number, kernel number per spike and 1000-kernel weight were 50.5, 1.3 and 0.9, respectively.

\section{Discussion}

\subsection{Soil water storage}

Under the same precipitation (Figure 1) and irrigation conditions, the significantly different soil water storage between UR and WN (Figure 4) clearly demonstrated the varying effects of row spacing on soil water use efficiency (WUE) and soil water evaporation during different seasons of winter wheat growing. Furthermore, different row spacing of $\mathrm{WN}$ with fewer numbers of furrow openers or seeding devices can help to facilitate wheat seeder to pass through the heavy residue load with less blocking than the uniform row spacing of UR. For WN, there was enough space among seeding devices to let straw pass through, in this mode straw was more likely to be moved to no-till belt and left less straw on surface of tilled seed belt. Straw mulching could influence water loss capacity of soil, water infiltration, retention 
and evaporation ${ }^{[23]}$. As evaporation form the soil depends upon the cover of bare soil exposed to $\operatorname{sun}^{[13]}$, UR improved drought tolerance by minimizing evaporation losses and led to its higher soil water storage. In particular, when winter wheat was experiencing green-up and plant growth during March to June, the more favorable ventilation and greater soil temperature of $\mathrm{WN}$ (Figure 5) may potentially enhance the winter wheat growth (demonstrated by the greater crop yield from the WN in Table 3). This suggested that the better growing winter wheat WN probably demanded and thus consumed more soil water than UR, possibly also contributing to better water use efficiency and thus resulting in lower soil water storage under the $\mathrm{WN}^{[16]}$. However, such differences in soil water storage were not evident during October and November. This probably can be attributed to two reasons: 1) the freshly sown winter wheat had limited demand on soil water, thus barely posing persistent effects on soil water storage; 2) the irrigation events during each November probably just overruled all the possible difference in soil water storage between the $\mathrm{WN}$ and UR. These results of this study agreed with findings of a similar study ${ }^{[24]}$ and demonstrated that the water losses with evaporation rise if soil surface is bare and straw mulching provides more surface cover improving soil water conservation.

\subsection{Soil temperature}

Under the same air temperature, WN had a higher soil temperature than UR, as well as the speed of warming up, during the three years' experiment at both $5 \mathrm{~cm}$ and $15 \mathrm{~cm}$ soil depth (Figure 5). This may be caused by the reason that $\mathrm{WN}$ provides little shelter, which means that WN ground can get more solar radiation and warm up. Although, IPAR of WN was greater, there was still more solar radiation hitting on the ground because of the wide-narrow row spacing arrangement. Meanwhile, straw mulching reduced soil radiation absorption ${ }^{[25]}$, with fewer residues covered and more sun exposure, snow was easy to melt and soil temperature went higher on seed belts of WN. The heavy residue could prevent the snow from melting and resist the warming up of soil, so the soil temperature of UR was always lower than WN during the three years in our study.

Both plant growth and development are affected by soil temperature ${ }^{[26]}$. The lower soil temperature in winter can freeze wheat root of winter wheat, slow down the process of root system recover and inhibit absorption speed of water and nutrition, which will have adverse effects on later stage of wheat growth; low soil temperature in early spring will freeze leaf, stem and spike of winter wheat, resist the transportation of water and nutrition for photosynthesis, substantially influenced grain growth and lead to reduction in yield ${ }^{[25]}$. The lower soil temperature under more straw mulching in spring delayed the development of winter wheat up to $7 \mathrm{~d}$, which on average reduced the final grain yield compared with no mulching.

\subsection{Photosynthesis and LAI}

Leaf is an important organ for plants to utilize sun radiation and produce organic matter. LAI has been related to crop growth, the fraction of absorbed photo-synthetically active radiation, crop condition and crop yield ${ }^{[27]}$. In this study, LAI of WN was significantly higher than that of UR, and WN created a better canopy structure than that of UR, which resulted in better intercepted photosynthetically active radiation, and consequently affect Leaf Area Index. Grain yield is directly related to the photosynthesis ability of leaves ${ }^{[28]}$ and PAR may have more relationships than traditional growth analysis techniques ${ }^{[29]}$.

Canopy light environment was improved and radiation use efficiency was significantly increased under narrow-wide row space planting $\operatorname{modes}^{[30]}$, and differences in canopy light interception characteristics may be the primary factors responsible for differences in the pattern of biomass accumulation ${ }^{[31]}$, so that IPAR lead to significant differences in final grain yield. However, in late May of 2013 and 2014 and early May in 2012 and 2013 the results were not significantly different and that may affected by improper sun's position and test values might be not accurate.

\subsection{Wheat yield and some yield components}

Yield components including the spike number, kernel number per spike and 1000-kernel weight was the primary contributing factor to yield formation. There should be a positively strong relationship between yield components and wheat yield. Higher yield components led to higher wheat yield, and proved that higher LAI and IPAR did increase crop growth, dry matter accumulation and in the end contribute to wheat yield. There were amount of research illustrate that wide-narrow row space planting mode could increase crop yield in different degree. Wide-narrow row space arrangement with appropriate plant density could improve seed yield for direct-seeded canola ${ }^{[10]}$. Compared with wide narrow and uniform row space under conventional tillage in different maize cultivar, the production of wide narrow was the highest ${ }^{[32]}$.

Edge growth effect is one of the rational reasons, well-ventilated condition, higher soil temperature, more sun exposure and suitable irrigation work together to provide higher yield of WN. More specially, for no or reduced tillage straw mulching also plays an important role in crop yield. Row spacing of $\mathrm{WN}$ is wide enough to provide ample room for stacking straw into no-till belts and leave relatively clean belts for seeding. The clean belts without amounts of straw can make sure seeds are placed into moisture soil rather than lay on straw or residue.

\section{Conclusions}

Results of this study demonstrated that WN had a positive impact on higher crop yield in North China Plain. The improved parameters included photosynthetically active radiation, LAI, the usage rate of soil water. Comparing with the UR, the IPAR and LAI of WN enhanced by $4.8 \%$ and $5.2 \%$, respectively, and the wheat yield increased by $519 \mathrm{~kg} / \mathrm{hm}^{2}(7.2 \%$ higher $)$.

Based on these results, wide-narrow row space planting mode for no or reduced tillage seeding when spacing between two rows of wheat seeds was " $10 \mathrm{~cm}+30 \mathrm{~cm}+10 \mathrm{~cm}+30 \mathrm{~cm}$ ", could be considered as an optimum cultivation practice for current winter wheat planting in North China Plain. It brought a high LAI and IPAR, and shall increase yield。Meanwhile, the wider row spacing let seeder performs more reliably on heavy straw conservation tillage seeding.

\section{Acknowledgments}

This study was financially supported by the Special Fund for Agro-scientific Research in the Public Interest from the Ministry of Agriculture, China (Grant No. 201503136); Modern Agricultural Industry Technology System (Grant No. CARS-03); and the Program for Changjiang Scholars and Innovative Research Team in University of China (Grant No. IRT13039).

\section{[References]}

[1] Yao M Z, Li B, Wang T L, Feng X. Effects of straw size in buried straw layers on water movement in adjacent soil layers. Int J Agric \& Biol Eng, 2016; 9(2): 74-84

[2] Vita P D, Paolo E D, Fecondo G, Fonzo N D, Pisante M. No-tillage and 
conventional tillage effects on durum wheat yield, grain quality and soil moisture content in southern Italy. Soil and Tillage Research, 2007; 92(1-2): 69-78.

[3] Nangia V, Ahmad M, Du J T, Yan C R, Hoogenboom G, Mei X R, et al. Effects of conservation agriculture on land and water productivity in Yellow River basin, China. Int J Agric \& Biol Eng, 2010; 3(2): 5-18.

[4] Pittelkow C M, Liang X Q, Linquist B A, van Groenigen K J, Lundy M E, van Gestel N, et al. Productivity limits and potentials of the principles of conservation agriculture. Nature, 2015; 517: 365-368.

[5] Derpsch R, Friedrich T, Kassam A, Li H W. Current status of adoption of no-till farming in the world and some of its main benefits. Int J Agric \& Biol Eng, 2010; 3(1): 1-25.

[6] Sun X Y, Zhao H J. The reasons for high yield of seedling transplanting summer maize and its cultivation techniques. Jiangsu Agricultural Sciences, 1989; 11: 11-13. (in Chinese)

[7] William F S, Stewart B W. Wide row spacing for deep-furrow planting of winter wheat. Field Crops Research, 2014; 168: 57-64.

[8] Testa G, Reyneri A, Blandino M. Maize grain yield enhancement through high plant density cultivation with different inter-row and intra-row spacings. Eur J Agron, 2016; 72: 28-37.

[9] Mao X M, Shen P J, Zhao Y X, Zhou X B. Effects of spatial distribution on photosynthesis and yield of summer maize. Banfladesh Journal of Botany, 2018; 47(1): 115-121.

[10] Wang R, Cheng T, Hu L. Effect of wide-narrow row arrangement and plant density on yield and radiation use efficiency of mechanized direct-seeded canola in Central China. Field Crops Research, 2015; 172: $42-52$.

[11] Frederick J R, Bauer P J, Busscher W J, Mccutcheon G S. Tillage management for double cropped soybean grown in narrow and wide row width culture. Crop Science, 1998; 38(3): 755-762.

[12] Khan I A, Hussain Z, Bakht T, Luqman. Plant spacing and mulching together affect the phenology and yield of tomato crop. The Journal of Animal \& Plant Sciences, 2018; 28(2): 546-551.

[13] Hussain M, Waqas-Ul-Haq M, Farooq S, Jabran K, Farooq M. The impact of seed priming and row spacing on the productivity of different cultivars of irrigated wheat under early season drought. Experimental Agriculture, 2016; 52(3): 477-490

[14] Sun L. Research on wide-narrow distance transplanting mechanism with the requirement of spatial trajectoary and attitude. $\mathrm{PhD}$ dissertation. Zhejiang Sci-Tech University, 2014; 148p.

[15] Liu W R, Zheng J Y, Feng Y C, Liu F C, Luo Y, Li W T, et al. Research on soil moisture variable rule of maize planted in wide-narrow row alternation form with protective cultivation technique. Journal of Maize Sciences, 2006; 14(4): 114-116. (in Chinese)

[16] Wang Q J, Li H W, He J, Li W Y, Liu A D. Effects of wide-ridge and narrow-row no-till cultivation on soil water and maize yield. Transactions of the CSAE, 2010; 26(8): 39-43. (in Chinese)

[17] Feng R Y, Wang H J, Yan G Y, Guo F, Gao W, Chen W L, et al. Effects of wide and narrow row cultivation on canopy structure, photosynthetic characteristics and yield in spring maize of dryland. Crops, 2015; (5): 80-84. (in Chinese)

[18] Soil Survey Staff. Keys to Soil Taxonomy, 8th ed. USDA,
Washington, 1998.

[19] Huang J X, Sedano F, Huang Y B, Ma H Y, Li X L, Liang S L, et al. Assimilating a synthetic Kalman filter leaf area index series into the WOFOST model to improve regional winter wheat yield estimation. Agricultural and Forest Meteorology, 2016; 216: 188-202.

[20] Ercoli L, Mensuali A, Malorgio F, Serra G. Interception of photosynthetically active radiation, growth and production of bush bean (Phaseolus vulgaris L.). Agric. Mediterr, 1992; 122(3): 215-224.

[21] GalloKP, Daughtry C S T. Techniques for measuring intercepted andabsorbed photosynthetically active radiation in corn canopies. Agronomy Journal, 1986, 78(4): 752-756.

[22] Tewolde H, Sistani K R, Rowe D E, Adeli A, Tsegaye T. Estimating cotton leaf area index nondestructively with a light sensor. Agronomy Journal, 2005, 97(4): 1158-1163.

[23] Yao M Z, Li B, Wang T L, Feng X. Effects of straw size in buried straw layers on water movement in adjacent soil layers. Int J Agric \& Biol Eng 2016; 9(2): 74-84.

[24] Zinnur G, Ustun S, Mesut C A, Ismail O, Ahmet C. The influence of different tillage practices on water content of soil and crop yield in vetch-winter wheat rotation compared to fallow-winter wheat rotation in a high altitude and cool climate. Agricultural Water Management, 2015; 160: 84-97.

[25] Chen S Y, Zhang X Y, Pei D, Sun H Y, Chen S L. Effects of straw mulching on soil temperature, evaporation and yield of winter wheat: Field experiments on the North China Plain. Annals of Applied Biology, 2007; 150: 261-268.

[26] Yang Y H, Ding J L, Zhang Y H, Wu J C, Zhang J M, Pan X Y, et al. Effects of tillage and mulching measures on soil moisture and temperature, photosynthetic characteristics and yield of winter wheat. Agricultural Water Management, 2018; 201: 299-308.

[27] Zhao D D, Shen J Y, Lang K, Liu Q R, Li Q Q. Effects of irrigation and wide-precision planting on water use, radiation interception, and grain yield of winter wheat in the north china plain. Agricultural Water Management, 2013; 118(2): 87-92.

[28] Guo Z, Yu Z, Wang D, Shi Y, Zhang Y. Photosynthesis and winter wheat yield responses to supplemental irrigation based on measurement of water content in various soil layers. Field Crops Research, 2014; 166 : $102-111$.

[29] Ahmad S, Zia-Ul-Haq M, Ali H, Shad S A, Ahmad A, Maqsood M, et al. Water and radiation use efficiencies of transplanted rice (Oryza sativa L.) at different plant densities and irrigation regimes under semi-arid environment. Pakistan Journal of Botany, 2008; 40(1): 199-209.

[30] Liu T D, Song F B, Liu S Q, Zhu X C. Light interception and radiation use efficiency response to narrow-wide row planting patterns in maize. Australian Journal of Crop Science, 2012; 6(3): 506-513.

[31] Brodrick R, Bange M P, Milroy S P, Hammer G L. Physiological determinants of high yielding ultra-narrow row cotton: Canopy development and radiation use efficiency. Field Crops Research, 2013; 148: 86-94

[32] Liu C W. Study on technology of alternatice fallow high stubble about narrow/wide in maize. Master dissertation. Gansu Agricultural University, 2009; 68 p. 